\title{
Development of a Gas Chromatography-Time-of-Flight Method for Detecting Glucosinolate Metabolites and Volatile Organic Compounds in Kimchi
}

\author{
Ho Jin Kim, Mi Jin Lee, Suel Hye Hur, and Min Hee Jeong \\ National Agricultural Products Quality Management Service, Gimcheon 39660, Republic of Korea \\ Correspondence should be addressed to Min Hee Jeong; miniya33@korea.kr
}

Received 22 March 2021; Revised 25 May 2021; Accepted 3 June 2021; Published 18 June 2021

Academic Editor: Barbara Bojko

Copyright (c) 2021 Ho Jin Kim et al. This is an open access article distributed under the Creative Commons Attribution License, which permits unrestricted use, distribution, and reproduction in any medium, provided the original work is properly cited.

\begin{abstract}
This study examined the volatile organic compounds (VOCs) and metabolites of glucosinolate (GLS) contained in kimchi and analyzed GLS using myrosinase. The analysis was conducted using gas chromatography-time of flight (GC-TOF), and VOC and the metabolite quantities were detected and analyzed. Based on 22 samples, tests were conducted, and 12 metabolites and 52 VOCs were found. When the detected metabolites were compared in general, the rate of isothiocyanate, which is well known for its anticancer effects and various other activities, was the highest. A total of 52 VOCs, including 15 aliphatic hydrocarbons, 7 acids, and 6 alcohols, were detected by GC-TOF. Therefore, the analytical methods provide a good basis to examine VOC and GLS metabolites; furthermore, the methods are of great help to secure excellent kimchi and evaluate its quality.
\end{abstract}

\section{Introduction}

Traditional fermented food, kimchi, was certified by Codex Alimentarius in July 2001 and is recognized as a global dish that is distinct from other types of pickles [1]. It is made by adding various ingredients (chili pepper powder, garlic, ginger, spring onion, radish, etc.) and salted seafood to cabbage, the main ingredient, which is then fermented at low temperature based on lactic acid bacteria [2-4]. The unique flavor of kimchi is derived from the ingredients and produced during the fermentation process. Kimchi is rich in vitamins and minerals, and it is a low-calorie food that plays an important role in reducing cholesterol. One of the effects of kimchi is its anticancer effect, which is promoted by minor ingredients of kimchi, namely, garlic and dried red pepper powder [5].

Kimchi contains glucosinolate (GLS), which is one of the main components of Cruciferae, metabolites, and volatile organic compounds (VOCs). First, GLS and its decomposition products are known for excellent effects. As shown in Figure 1, GLS decomposes into isothiocyanate (a bioactive substance), nitrile (a toxic compound), thiocyanate, oxazolidine-2-thiones, and thiocyanates, as well as epithionitriles and glucosevia, the myrosinase enzyme [6].

Isothiocyanates are involved in the defense mechanism of plants, offering strong antibacterial and insecticidal attributes, as well as strong flavor; isothiocyanates also help prevent cancers, such as liver, lung, and stomach cancers in human beings $[7,8]$. Particularly, sulforaphane (the isothiocyanate of glucoraphanin) and indole-3-carbinol (the isothiocyanate of glucobrassicin) are excellent contributors to the anticancer effect of kimchi [9-11]; according to experimental and statistical results reported in other studies, the prevalence of breast cancer can be reduced with the consumption of crucifers [12]. In animal testing, tumors causing skin cancer were suppressed by increasing consumption of crucifers [13]. Furthermore, sulforaphane reduces the size and occurrence of tumors, as well as delays their growth [14]. Sulforaphane is also known to promote defense mechanisms against insects and pathogens and to be involved in sulfur, nitrogen, and glucose metabolism [15]. In addition, sulforaphane influences hormone auxin levels, and it influences colon, lung, and prostate cancers in human beings with anticancer compounds [16]. Many pharmacological and 


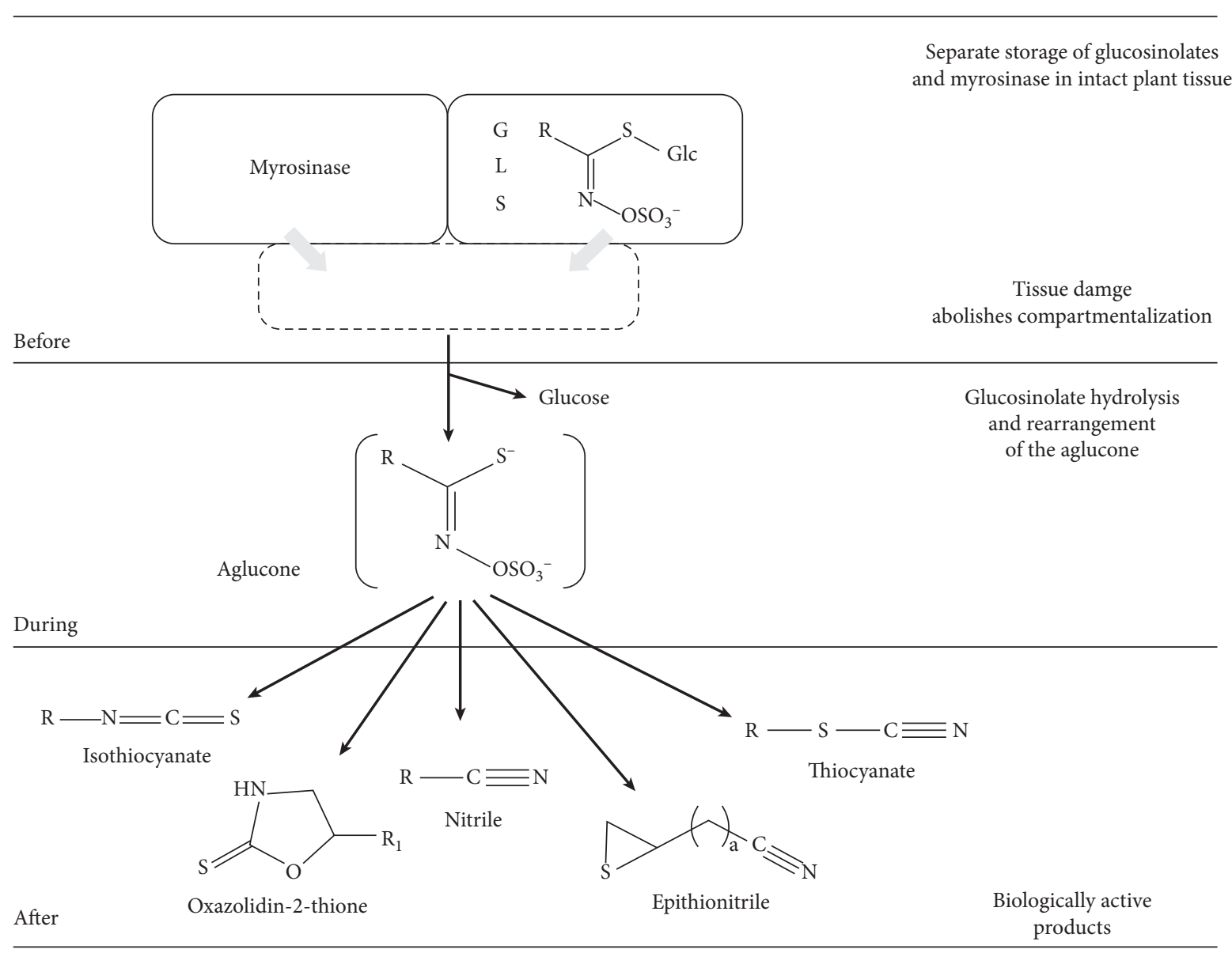

FIgURE 1: Functional and biological implications of the myrosinase-glucosinolate system.

physiological activities have been reported, among many other research studies on these compounds in kimchi [9-11]. Accordingly, for GLS, various studies have been conducted on the VOC composition and discrimination of GLS decomposition products in crucifers [17]; one study on GLS in serum, using LC-MS/MS and its decomposition products, was also completed [18]. However, studies on GLS metabolites are lacking.

VOCs are known to have the most powerful effects on the sourness, organoleptic properties, and palatability of kimchi [19]. There are various types of VOCs, such as dimethyl sulfides, sulfide, isothiocyanates, aldehydes, ketones, and alcohols. In relevant research, 25 VOCs collected by SPME [20], 40 types of sulfides [21], and GLS-derived VOCs [6] were identified.

Many analytical instruments have been recently developed to provide many advantages, including decreasing analysis time, saving sample and extraction solvent amounts, detecting minute amounts with high sensitivity, separating mixtures, identifying structures, and analyzing minute samples. Moreover, the appearance of TOF recently is advantageous to measure the exact mass with high resolution, high sensitivity, and strengthened selectivity [22-25]. Because properties that could not be analyzed before have since become resolvable using these analytical instruments, it has become possible to develop new analytical methods.
This study investigated GLS and VOC metabolites in myrosinase-treated kimchi using GC-TOF. The manufacturers and ingredients of various kimchi samples were used to analyze the GLS metabolites and VOCs. The findings can be used to verify the benefits of kimchi and the use of various cruciferous vegetables.

\section{Materials and Methods}

2.1. Samples, Chemicals, and Reagents. Tests were made with various kinds of kimchi purchasable in local marts; a total of 22 samples were used. In the experiment, 22 kimchi were sliced and prefreezed for 48 hours at $-40^{\circ} \mathrm{C}$. After that, it is freezedried in a dryer at $-70^{\circ} \mathrm{C}$ for 24 hours. Freeze-dried kimchi was pulverized using a food-mixer blender and filtered with a 3 mesh size. Water was purified using a Milli-Q ${ }^{\circledR}$ RiOsTM/Elix ${ }^{\circledR}$ water purification system (Millipore, Bedford, MA, USA). Myrosinase enzymes and L-ascorbic acid were purchased from Sigma (St. Louis, MO, USA). Dichloromethane was purchased from Merck KGaA (Darmstadt, Germany). Anhydrous sodium sulfate was purchased from Dae Jung.

2.2. Sample Preparation. $5 \mathrm{~g}$ of the lyophilized sample was placed in a volumetric flask, and $250 \mathrm{~mL}$ of distilled water, 5 units of myrosinase enzyme, and $5 \mathrm{mg}$ of L-ascorbic acid were 


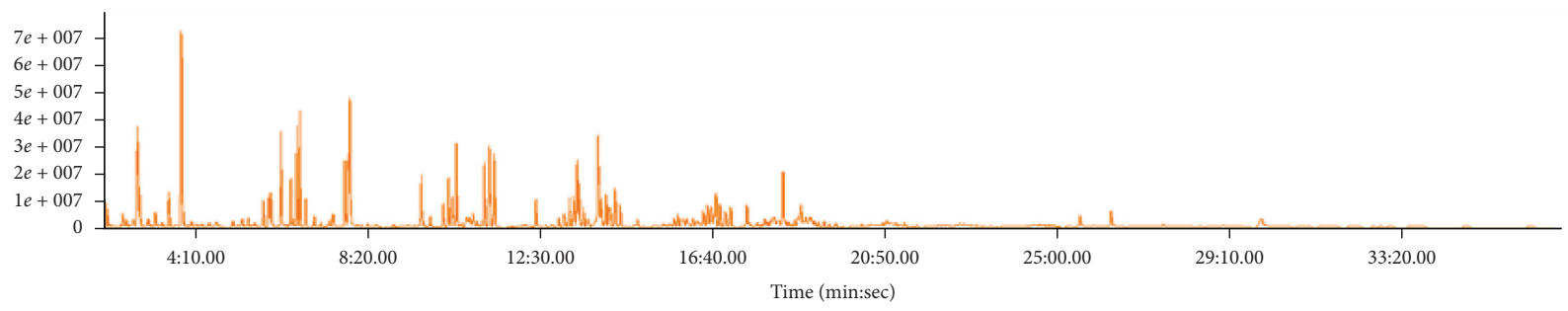

(a)

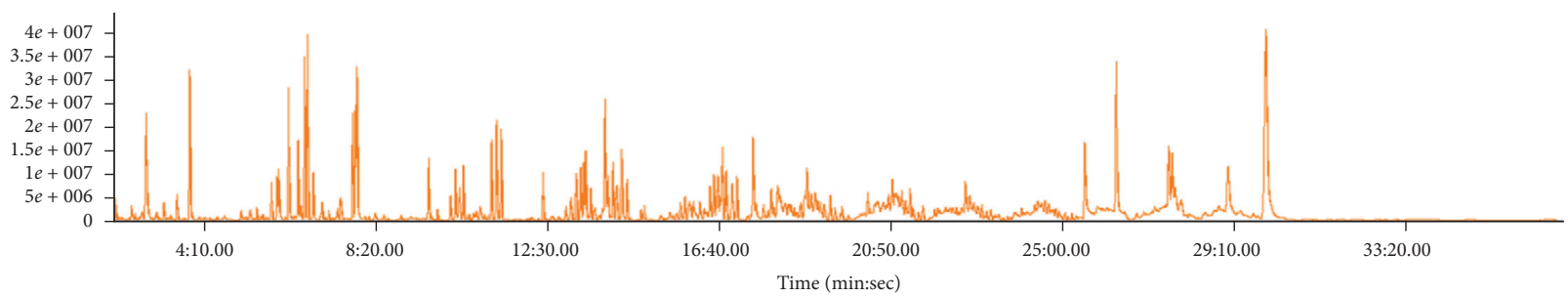

(b)

Figure 2: TIC (total ion chromatogram) of samples 17 (a) and 21 (b).

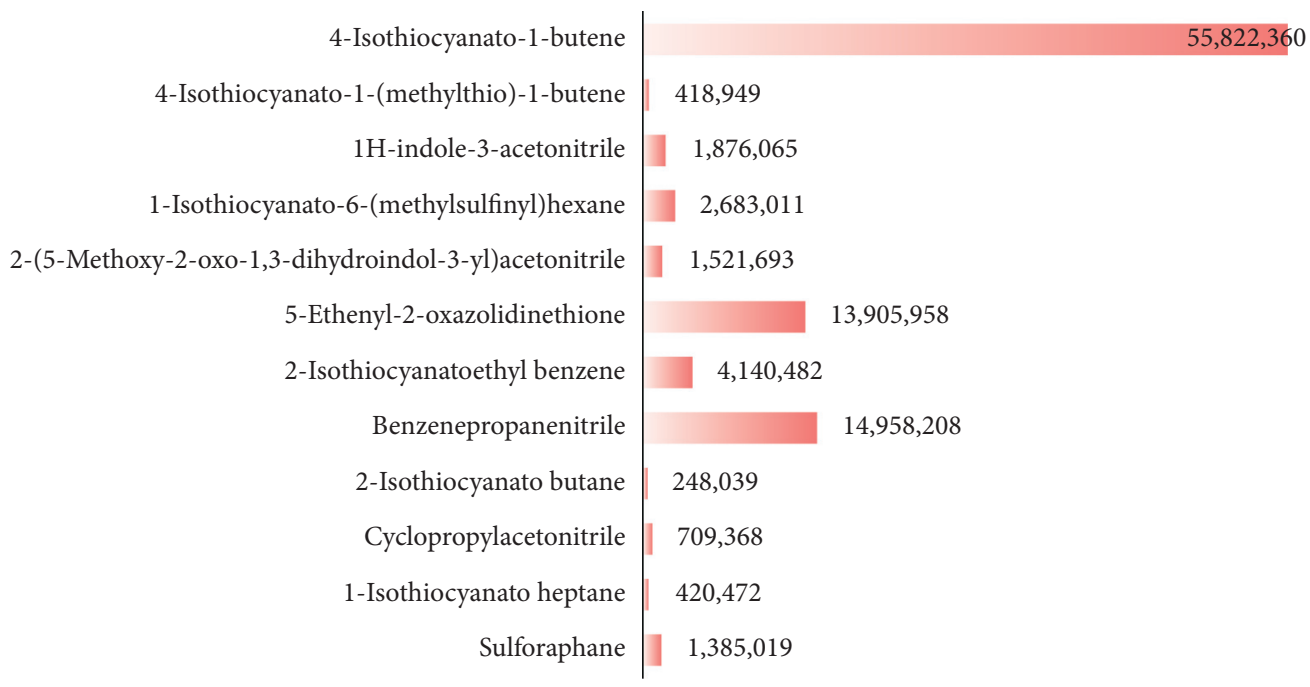

Figure 3: Average area of glucosinolate metabolites in kimchi.

added to the mixture. The mixture was then kept at room temperature for 2 hours. Then, $100 \mathrm{~mL}$ of dichloromethane was added and stirred for 30 minutes. The layers were separated by centrifugation at 3,500 rpm for 15 minutes. The separated organic solvent layer was passed through anhydrous sodium sulfate, and the sample was then concentrated in a rotary evaporator until $0.5 \mathrm{~mL}$ of the sample remained. After the concentrate temperature reached $-20^{\circ} \mathrm{C}$, the sample was tested.

2.3. GC-TOF Analysis. GC was performed on an HP 7890 GC (Agilent Technologies, Santa Clara, CA, USA), and the injector was used on a rail system (CTC, Gerstel, LEAP). The injection temperature was set at $250^{\circ} \mathrm{C}$, and the injection type was set at split 10:1 mode. The other experimental parameters were set as follows: carrier gas $\mathrm{He}$, flow rate
$1.5 \mathrm{~mL} / \mathrm{min}$, column RTX-5 MS $30 \mathrm{~m} \times 0.25 \mathrm{~mm} \times 0.25 \mu \mathrm{m}$, and transfer line temperature $\left(260^{\circ} \mathrm{C}\right)$.

Detection was performed on a LECO $^{\circledR}$ PegasusHT ${ }^{\circledR}$ TOF-MS and controlled using a Chroma TOF (LECO, St. Joseph, MI, USA). The other experimental parameters were set as follows: acquisition delay $130 \mathrm{~s}$, mass range (5-650 $\mu$, acquisition rate 10 spectra/s, detector voltage $1650 \mathrm{~V}$, electron energy $70 \mathrm{eV}$, and ion source temperature $250^{\circ} \mathrm{C}$.

\section{Results and Discussion}

Tests were conducted based on 22 samples purchasable in marts and repeated three times. VOC and metabolites of GLS ingredients were detected in all 22 samples (Figure 2) with an $\mathrm{S} / \mathrm{N}$ ratio of more than 50 . The results are shown in Sections 3.1 and 3.2. 
TABLE 1: Structure of glucosinolate metabolites in kimchi.

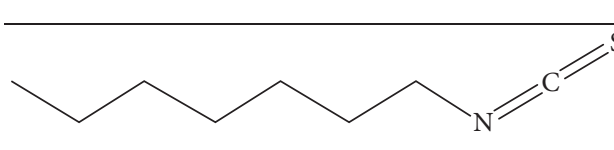

1-Isothiocyanato heptane

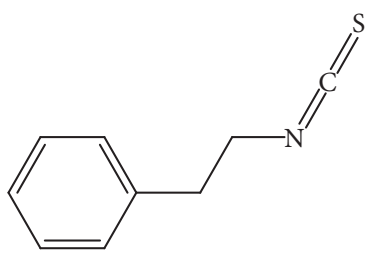

Benzene, (2-isothiocyanatoethyl)-

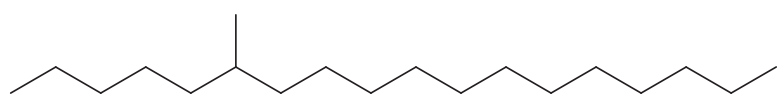

4-Isothiocyanato-1-(methylthio)-1-butene<smiles>CS(=O)CCCCN=C=S</smiles>

Sulforaphane<smiles>C=CC1CNC(=S)O1</smiles>

Benzenepropanenitrile<smiles>COc1ccc2c(c1)C(CC#N)C(=O)N2</smiles>

2-(5-Methoxy-2-oxo-1,3-

dihydroindol-3-yl)acetonitrile

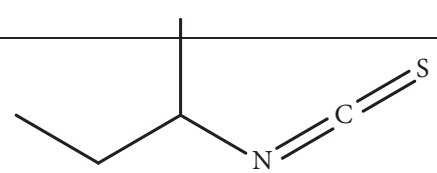

2-Isothiocyanato-butane

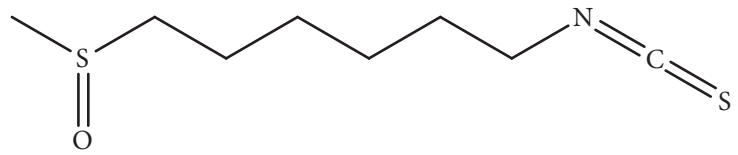

1-Isothiocyanato-6-(methylsulfinyl)hexane
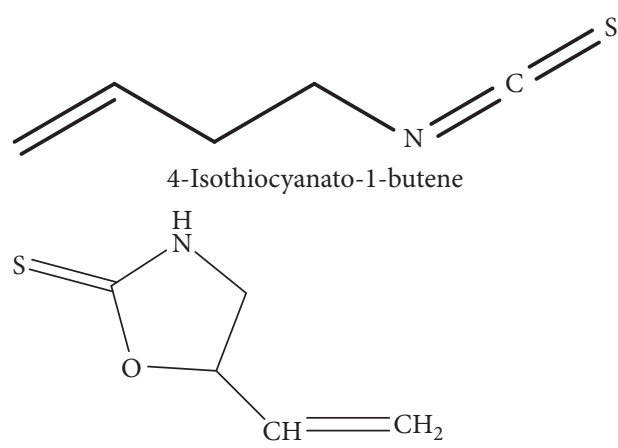

2-Oxazolidinethione, 5-ethenyl-

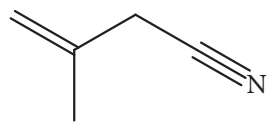

Cyclopropylacetonitrile

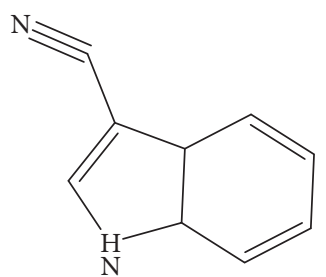

1H-indole-3-acetonitrile

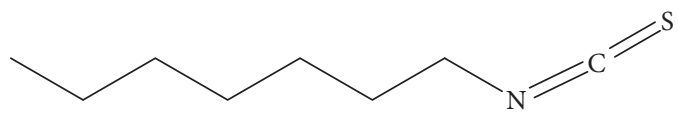

trans-Raphasatin

3.1. Composition Analysis of Glucosinolate Metabolite in Kimchi. GLS metabolites can be largely divided into the following five types: isothiocyanate, oxazolidin-2-thione, nitrile, epithionitrile, and thiocyanate. In this study, 7 istiocyanates, 1 oxazolidin-2-thione, and 4 nitriles were detected. The 12 GLS metabolites were classified based on the GC library, and the sample area was confirmed. First, there were 7 isothiocyanates including 1-isothiocyanato heptane, 2-isothiocyanato butane, and 2-isothiocyanatoethyl benzene, and sulforaphane was identified as a glucoraphanin metabolite, which is a type of GLS (found in the GLS comparative study). This suggests that samples containing sulforaphane have glucoraphanin. On average, 4-isothiocyanato-1-butene was the largest at 55,822,360, especially in samples 17 and 21, which had values of 229,507,199 and 278,971,384, respectively. In addition, in samples 17 and 21, 2isothiocyanatoethyl benzene was also found in large quantities of 37,200,818 and 39,458,110, respectively; however, the compound was present in all samples. The average area of oxazolidin-2-thione class metabolites was 13,905,958, and the 
TABle 2: Classified VOCs.

\begin{tabular}{|c|c|c|c|}
\hline NO. & Compound & Chemical group & Reference \\
\hline 1 & 1-Penten-3-one & Ketone & {$[26]$} \\
\hline 2 & 2-Methyl-2-butenal & Aldehyde & {$[26]$} \\
\hline 3 & cis-3-Hexenal & Aldehyde & {$[26]$} \\
\hline 4 & Di-2-propenyltrisulfide, & S-containing compounds & {$[21]$} \\
\hline 5 & Diallayldisulphide & S-containing compounds & {$[21]$} \\
\hline 6 & Dimethyl tetrasulphide & S-containing compounds & {$[21]$} \\
\hline 7 & Farnesene & Terpene hydrocarbons & {$[21,28]$} \\
\hline 8 & Sesquiphellandrene & Terpene hydrocarbons & {$[21,28]$} \\
\hline 9 & Sabinene & Terpene hydrocarbons & {$[21,28]$} \\
\hline 10 & (-)-Pinene & Terpene hydrocarbons & [28] \\
\hline 11 & Camphene & Terpene hydrocarbons & {$[28]$} \\
\hline 12 & 2,4-Dimethyl- heptane & Aliphatic hydrocarbons & {$[28]$} \\
\hline 13 & 4,6-Dimethyl- dodecane & Aliphatic hydrocarbons & {$[28]$} \\
\hline 14 & Tetradecane & Aliphatic hydrocarbons & {$[28]$} \\
\hline 15 & Hexadecane & Aliphatic hydrocarbons & {$[28]$} \\
\hline 16 & 1,3-bis (1,1-Dimethylethyl)- benzene & Miscellaneous compounds & {$[28]$} \\
\hline 17 & Butanoic acid & Acids & {$[27]$} \\
\hline 18 & iso-Valeric acid & Acids & [27] \\
\hline 19 & 2-Methylbutanoic acid & Acids & {$[27]$} \\
\hline 20 & n-Hexadecanoic acid & Acids & {$[27]$} \\
\hline 21 & 3-Methyl-1-butanol, & Alcohols & {$[27]$} \\
\hline 22 & 3-Methyl-2-buten-1-ol & Alcohols & {$[27]$} \\
\hline 23 & Linalool & Alcohols & [27] \\
\hline 24 & Eugenol & Alcohols & {$[27]$} \\
\hline 25 & (R)- 5,6,7,7a-tetrahydro-4,4,7a-trimethyl-2 (4H)-benzofuranone & Ketone & {$[27]$} \\
\hline 26 & Dodecane & Aliphatic hydrocarbons & {$[27]$} \\
\hline 27 & 1-Dodecane & Aliphatic hydrocarbons & {$[27]$} \\
\hline 28 & 1-Tetradecene & Aliphatic hydrocarbons & {$[27]$} \\
\hline 29 & Benzeneacetaldehyde & Aldehyde & [29] \\
\hline 30 & Nonadecane & Alkane & [29] \\
\hline 31 & Octadecane & Alkane & [29] \\
\hline 32 & Hexadecanoic acid & Acids & [29] \\
\hline 33 & Pentadecane & Alkane & [29] \\
\hline 34 & Dimethyl disulfide, & S-containing compounds & {$[20]$} \\
\hline 35 & Hexanoic acid & Acids & {$[20]$} \\
\hline 36 & Octanoic acid & Acids & {$[20]$} \\
\hline 37 & 4-Methyl-1-penten-3-ol & Ketone & [26] \\
\hline 38 & 3-Methyl-2-butenal & Aldehyde & {$[26]$} \\
\hline 39 & 1-Hexen-3-ol & Alcohols & {$[26]$} \\
\hline 40 & 2-Pentanone & Ketone & [26] \\
\hline 41 & 2,3,5-Trimethyl- hexane & Aliphatic hydrocarbons & {$[28]$} \\
\hline 42 & 2,3,4-Trimethyl- hexane & Aliphatic hydrocarbons & {$[28]$} \\
\hline 43 & 4,4,5-Trimethyl-2-Hexene, & Aliphatic hydrocarbons & {$[28]$} \\
\hline 44 & 3,5,5-Trimethyl-2-Hexene, & Aliphatic hydrocarbons & {$[28]$} \\
\hline 45 & 3,5,5-Trimethyl-1-Hexene, & Aliphatic hydrocarbons & {$[28]$} \\
\hline 46 & 2,3,3-Trimethyl-1-hexene & Aliphatic hydrocarbons & {$[28]$} \\
\hline 47 & 4,4-Dimethyl- heptane, & Aliphatic hydrocarbons & {$[28]$} \\
\hline 48 & 2,3-Dimethyl- heptane, & Aliphatic hydrocarbons & {$[28]$} \\
\hline 49 & 3-Penten-2-ol & Ketone & {$[27]$} \\
\hline 50 & 3-Methyl-3-buten-1-ol & Alcohols & {$[27]$} \\
\hline 51 & 2-Octene & Alkene & {$[27]$} \\
\hline
\end{tabular}

area was observed only in samples 17 and 21. Among nitrile metabolites, cyclopropylacetonitrile, benzenepropanenitrile, 2-(5-methyoxy-2-oxo-1,3-dihydroindol-3-yl) acetonitrile, and $1 \mathrm{H}$-indole-3-acetonitrile were found. Benzenepropanenitrile was observed in the highest content with an area of 0-39,724,396 (average 14,958,208). More detailed results are presented in Figure 3, Table 1, and Table S1 [20, 21, 26-29].
3.2. Composition Analysis of Kimchi VOC. Table 2 classifies VOCs detected in the 22 samples according to class. In total, 52 VOCs were observed, specifically aliphatic hydrocarbons (15), acids (7), alcohol (6), alkane (5), ketone (5), aldehyde (4), S-containing compounds (4), terpene hydrocarbons (5), and a miscellaneous compound (1) (Table 2). The largest areas were occupied by 2, 3, 4-trimethyl hexane $(214,485,249), 4$, 6- 

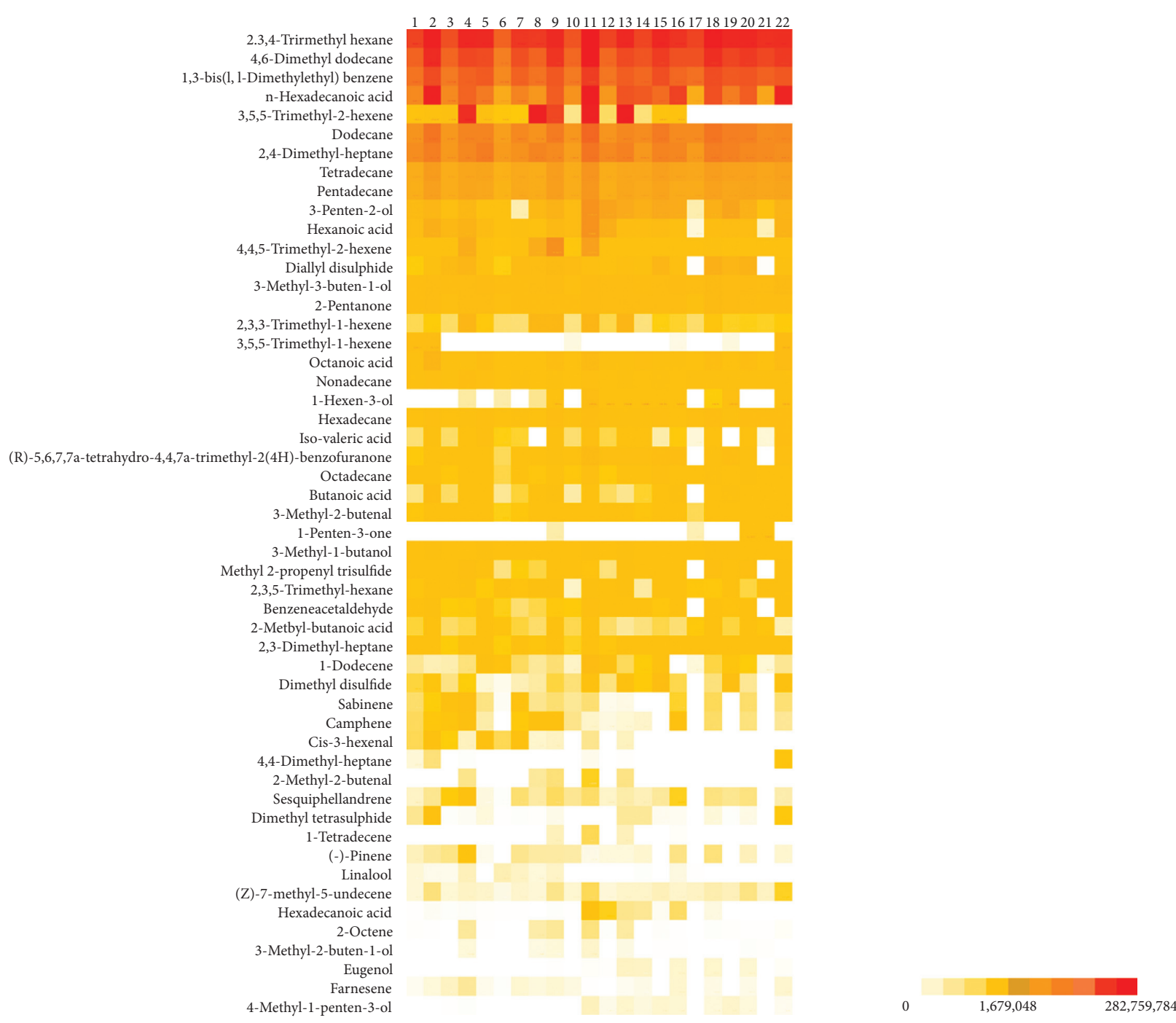

Figure 4: Heat map of volatile organic compounds (VOCs) in kimchi.

dimethyl dodecane $(176,577,662), 1,3$-bis (1,1-dimethylethyl), and benzene $(139,454,474)$, in that order. A comparison of the sample areas showed that samples 11 and 18 of 2,3,4-trimethyl hexane had the largest areas (275,021,365 and 263,894,944, respectively). Among the 52 compounds, only 21 were observed in all samples, with the average area of $145,926-214,485,249$. The overall results are presented in Figure 4 and Table S2. The mass spectrum and structure are shown in Table 2 and Figure S1.

\section{Conclusions}

The cell walls of Brassicaceae plants contain an enzyme called myrosinase. When external animals and insects destroy the cell wall or the cell wall is destroyed by microorganisms or bacteria, an enzyme called mirosinase is released. The enzymes in myrosinase break down GLS, resulting in the production of secondary metabolites. In kimchi, 51 compounds of VOCs and GLS metabolite were detected by GC-TOF. This analysis technique was used for analyzing VOCs and GLS metabolites contained in kimchi, based on myrosinase treatment. For the analysis, GC-TOF was used in comparison with the library and to identify the compounds. As a result, in 22 samples, 12 GLS metabolites and 51 VOCs were observed. The findings of GLS metabolites and the GC-TOF analysis technique in this study can provide useful data for relevant analyses and quality assessments, as well as provide evidence of the excellence and reliability of kimchi.

\section{Data Availability}

All data are included within the article and the supplementary materials.

\section{Conflicts of Interest}

The authors declare that there are no conflicts of interest regarding the publication of this paper. 


\section{Authors' Contributions}

Ho Jin Kim and Mi Jin Lee contributed equally to this work.

\section{Supplementary Materials}

More detailed composition analysis of glucosinolate metabolite and VOC are presented. Table 1: area of glucosinolate metabolites. Table 2: area of volatile oragnic compounds. Figure S1: GC-TOF of mass spectrum and structure of compounds. (Supplementary Materials)

\section{References}

[1] S.-W. Moon, H.-K. Shin, and G.-E. Gi, "Effects of xylitol and grapefruit seed extract on sensory value and fermentation of baechu kimchi," Korean Journal of Food Science and Technology, vol. 35, pp. 246-235, 2003.

[2] W.-S. Park, I.-S. Lee, Y.-S. Han, and Y.-J. Koo, "Kimchi preparation with brined Chinese cabbage and seasoning mixture stored separately," Korean Journal of Food Science and Technology, vol. 26, pp. 231-238, 1994.

[3] M.-K. Lee, K.-K. Rhee, J.-K. Kim, S.-M. Kim, J.-W. Jeong, and D.-J, Jang, A survey of research papers on Korean kimchi and R\&D trends," Journal of the Korean Society of Food Culture, vol. 6, pp. 104-114, 2007.

[4] I.-S. Lee, W.-S. Park, Y.-J. Koo, and K.-H. Kang, Changes in some characteristics of brined Chinese cabbage of fall cultivars during storage," Korean Journal of Food Science and Technology, vol. 26, pp. 239-245, 1994.

[5] E. J. Cho, S. H. Kim, K. Y. Park, and S. H. Rhee, "in vitro anticancer effect of active compounds from Chinese cabbage kimchi," Journal of Korean Association of Cancer Prevention, vol. 2, pp. 98-103, 2004.

[6] I. Winde and U. Wittstock, "Insect herbivore counteradaptations to the plant glucosinolate-myrosinase system," Phytochemistry, vol. 72, no. 13, pp. 1566-1575, 2011.

[7] P. Talalay, "Mechanisms of induction of enzymes that protect against chemical carcinogenesis," Advances in Enzyme Regulation, vol. 28, pp. 237-250, 1989.

[8] Y. Zhang, T. W. Kensler, C. G. Cho, G. H. Posner, and P. Talalay, "Anticarcinogenic activities of sulforaphane and structurally related synthetic norbornyl isothiocyanates," Proceedings of the National Academy of Sciences, vol. 91, no. 8, pp. 3147-3150, 1994.

[9] H. J. Kim, M. J. Lee, M. H. Jeong, and J. E. Kim, "Identification and quantification of glucosinolates in kimchi by liquid chromatography-electrospray tandem mass spectrometry," International Journal of Analytical Chemistry, vol. 2017, Article ID 6753481, 2017.

[10] P. J. Thornalley, "Isothiocyanates: mechanism of cancer chemopreventive action," Anti-Cancer Drugs, vol. 13, no. 4, pp. 331-338, 2002.

[11] J. D. Hayes, M. O. Kelleher, and I. M. Eggleston, "The cancer chemopreventive actions of phytochemicals derived from glucosinolates," European Journal of Nutrition, vol. 47, no. 2, pp. 73-88, 2008.

[12] P. Terry, A Wolk, I Persson, and C Magnusson, "Brassica vegetables and breast cancer risk," JAMA, vol. 285, no. 23, pp. 2975-2977, 2001.

[13] A. T. Dinkova-Kostova, S. N. Jenkins, J. W. Fahey et al., "Protection against UV-light-induced skin carcinogenesis in SKH-1 high-risk mice by sulforaphane-containing broccoli sprout extracts," Cancer Letters, vol. 240, no. 2, pp. 243-252, 2006.

[14] J. W. Fahey, X. Haristoy, P. M. Dolan et al., "Sulforaphane inhibits extracellular, intracellular, and antibiotic-resistant strains of Helicobacter pylori and prevents benzo[a]pyreneinduced stomach tumors," Proceedings of the National Academy of Sciences, vol. 99, no. 11, pp. 7610-7615, 2002.

[15] P. J. Thornalley, "Glycation in diabetic neuropathy: characteristics, consequences, causes, and therapeutic options," International Review of Neurobiology, vol. 50, pp. 37-57, 2002.

[16] K. A. Moy, J.-M. Yuan, F.-L. Chung et al., "Isothiocyanates, glutathioneS-transferase M1 and T1 polymorphisms and gastric cancer risk: a prospective study of men in Shanghai, China," International Journal of Cancer, vol. 125, no. 11, pp. 2652-2659, 2009.

[17] A. Luca, P. V. Mahajan, and M. Edelenbos, "Changes in volatile organic compounds from wild rocket (Diplotaxis tenuifolia L.) during modified atmosphere storage," Postharvest Biology and Technology, vol. 119, pp. 1-9, 2015.

[18] H. E. Sun, E. Y. Hong and G. H. Kim, Determination of bioactive compounds and anti-cancer effect from extracts of Korean cabbage and cabbage," The Korean Journal of Food and Nutrition, vol. 25, pp. 259-265, 2012.

[19] J. H. Seung, "Major odor components of raw kimchi materials and changes in odor components and sensory properties of kimchi during ripening," Journal of the Korean Society of Food Culture, vol. 25, pp. 607-614, 2010.

[20] J. Ha, "Analysis of volatile organic compounds in kinnchi absorbed in SPME by GC-AED and GC-MSD," Journal of the Korean Society of Food Science and Nutrition, vol. 31, no. 3, pp. 543-545, 2002.

[21] Y.-S. Lee, H.-S. Sohn, and J.-O. Rho, "Study on sensory properties and volatile flavor compounds of kimchi added with backryeoncho (opuntia ficus-indica var. saboten) extracts," Journal of the East Asian Society of Dietary Life, pp. 506-513, 2012.

[22] B. Ma, X. Li, Q. Zhang et al., "Metabonomic profiling in studying anti-osteoporosis effects of strontium fructose 1,6diphosphate on estrogen deficiency-induced osteoporosis in rats by GC/TOF-MS," European Journal of Pharmacology, vol. 718, no. 1-3, pp. 524-532, 2013.

[23] J. Ji, P. Zhu, F. Pi et al., "GC-TOF/MS-based metabolomic strategy for combined toxicity effects of deoxynivalenol and zearalenone on murine macrophage ANA-1 cells," Toxicon, vol. 120, pp. 175-184, 2016.

[24] J. G. Meher, N. P. Yadav, J. J. Sahu, and P. Sinha, "Determination of required hydrophilic-lipophilic balance of citronella oil and development of stable cream formulation," Drug Development and Industrial Pharmacy, vol. 39, no. 10, pp. 1540-1546, 2013.

[25] X. Wei, X. Shi, I. Koo et al., "MetPP: a computational platform for comprehensive two-dimensional gas chromatography time-of-flight mass spectrometry-based metabolomics," Bioinformatics, vol. 29, no. 14, pp. 1786-1792, 2013.

[26] L. Bell, N. D. Spadafora, C. T. Müller, C. Wagstaff, and H. J. Rogers, "Use of TD-GC-TOF-MS to assess volatile composition during post-harvest storage in seven accessions of rocket salad (Eruca sativa)," Food Chemistry, vol. 194, pp. 626-636, 2016.

[27] J. Y. Kim, E.-Y. Park, and Y.-S. Kim, "Characterization of volatile compounds in low-temperature and long-term fermented baechu kimchi," Journal of the Korean Society of Food Culture, vol. 21, pp. 319-324, 2006. 
[28] M. K. Yoon, S. M. Lee, J. W. Kim et al., "Characterization of volatile Components according to fermentation Periods in gamdongchotmoo kimchi," Korean Journal of Food Science and Technology, vol. 40, no. 5, pp. 497-502, 2008.

[29] Y.-H. Pyo, J.-S. Kim and Y.-S. Hahn, Volatile compounds of mustard leaf (Brassica juncea) kimchi and their changes during fermentation," Korean Journal of Food Science and Technology, vol. 32, no. 1, pp. 56-61, 2000. 